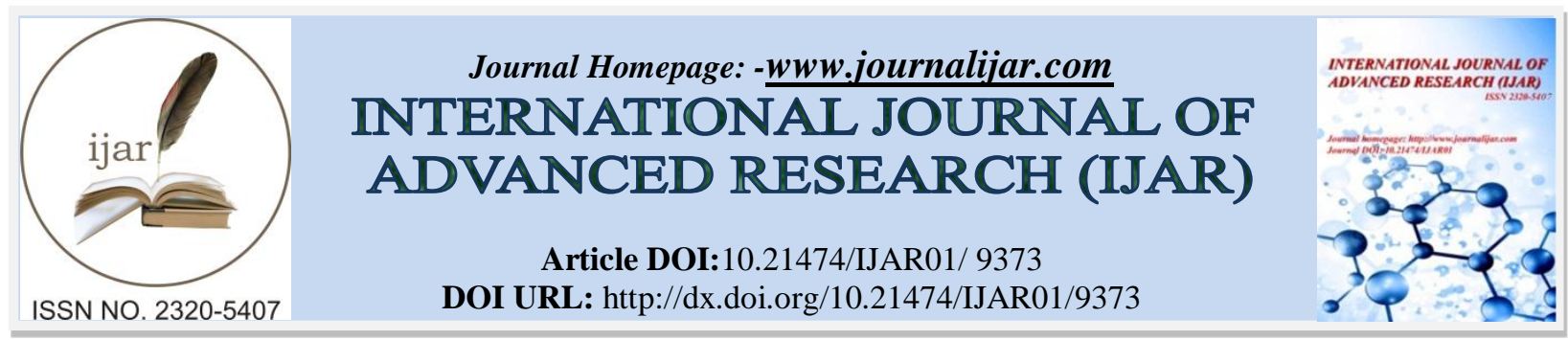

RESEARCH ARTICLE

\title{
IMPACT OF PHYSICAL ACTIVITY DURING PREGNANCY ON OBSTETRIC OUTCOMES IN TAIF, SAUDI ARABIA.
}

Farzana Rizwan Arain ${ }^{1}$, Jumanah Talal Al-Malki ${ }^{2}$, Nisreen Aref Al-bizrah ${ }^{3}$, Abrar Fahad Alotaibi ${ }^{2}$ and Wejdan Ali Mohammed Alshehri ${ }^{4}$.

1. Professor,Obstetrics \& gynecology department College of medicine, taif university, KSA.

2. Medical intern, taif university, KSA.

3. Associate, ProfessorObstetrics \& gynecology departmentCollege of medicine, taif university, KSA.

4. $6^{\mathrm{TH}}$ year Student, College of medicine, taif university, KSA.

\section{Manuscript Info}

Manuscript History

Received: 10 May 2019

Final Accepted: 12 June 2019

Published: July 2019

Key words:-

Birth weight, gestational age, health status, physical activity, pregnancy, vaginal delivery.

\section{Abstract}

Objective: To identify the impact of Physical Activity (PA) during pregnancy on obstetric outcomes.

Material And Methods: The descriptive cross-sectional study was conducted in the Department of Gynaecology and Obstetrics, King Faisal Maternity Hospital, situated in Taif city, Saudi Arabia from July to December, 2018. Three hundred women from maternity clinic, delivery rooms and those admitted in wards were recruited through non-probability convenience sampling technique. Women who delivered recently of age 18 to 45 years with no psychiatric illness and willing to give informed consent were invited to participate in this research. Primary data was collected using a structured closed ended questionnaire on socio demographic and maternal characteristics, physical activity during pregnancy, self-reported health status and obstetric outcomes (i.e. gestational age at delivery in week, birth weight, living status, admission to Neonatal Intensive Care Unit (NICU) and mode of delivery). Analysis was performed on SPSS version 21.

Results: The mean (SD) age in years of the study participant was 27.3 (4.6). Majority of study participants during pregnancy were overweight $(37 \%)$, followed by normal weight $(33 \%)$ and obese $(30 \%)$. Majority of the study participants were multiparous $(51 \%)$, followed by nullparity $(24 \%)$ and grand multipara (25\%). Important, around ninety eight percent of the study participants were non-smokers, while nineteen percent were passive smokers. There were only eighty one study participants (27\%) who affirmed managing 150 minutes/ week of moderate/ vigorous physical activities in leisure time. No significant difference was found in self-reported health status during pregnancy by the study participants having less than 150 minutes of PA per week (Group A) to those having 150 minutes or more time spent in PA per week (Group B). Significant difference was observed in gestational age at delivery in weeks between two groups (39.3 vs. 38.9 ; p-value = 0.0018), while no significant difference was identified in obstetric

Corresponding Author:-Farzana Rizwan Arain.

Address:-Professor,Obstetrics \& gynecology department College of medicine, taif university, KSA. 
outcomes (birth weights, living status, admission to NICU and mode of delivery) between the two groups.

Conclusion: The level of physical activity had significant impact on gestational age at delivery in weeks. Moreover, the recommended physical activity appeared to improve the obstetric outcomes; birth weight at delivery, living status, reduced NICU admission and mode of delivery as vaginal.

Copy Right, IJAR, 2019,. All rights reserved.

\section{Introduction:-}

Physical activity (PA) is a significant public health concern in the 21 st century. ${ }^{1}$ World Health Organisation (WHO) has defined PA as any bodily movement being produced by skeletal muscles contraction resulting in adequate caloric requirement that is required for energy expenditure. ${ }^{2}$ Four main types of physical activity are aerobic, stretching, muscle strengthening and bone-strengthening. ${ }^{2}$ Approximately one quarter (23.3\%) of the adult population was found to be physically inactive as reported by the survey conducted in $2016 .{ }^{3}$ The Global Burden of Disease (GBD) report of 2015, estimated that physical inactivity contributed to around 1.6 million deaths on account of increase in the risk of non-communicable disease (NCD); i.e. diabetes mellitus, ischemic heart disease, and colon/ rectal cancer. ${ }^{4}$ The epidemiological report published by WHO has reported that around $58 \%$ of the Saudi adult was found physically inactive. ${ }^{5}$ The national survey, further highlighted that around three fifth of the entire Saudi population was physically inactive. ${ }^{6}$ The high prevalence of physical inactivity among the Saudi population can be accountable due to economic development, modernization, transformation in life style, demographic changes and urbanization witnessed in last two decades. ${ }^{7}$

The American College of Obstetricians and Gynecologists (ACOG) has recommended that women with uncomplicated pregnancies should be encouraged to engage in physical activities before, during, and after pregnancy. ${ }^{8}$ However, during pregnancy the duration and intensity of physical activities must be less than prepregnancy. ${ }^{9}$ The ACOG has recommended different types of physical activities that can be performed by pregnant women including; walking, swimming, yoga, running and jogging. ${ }^{9}$ It is recommended for pregnant women to practice physical activities for 30 minutes or more of moderate exercise per day. ${ }^{10}$ In addition, the ACOG recommended the pregnant women to perform physical activity but before that medical evaluation should be done to make sure that women do not have any medical issues to avoid any danger resulted from the physical activity. ${ }^{10}$

Evidence from the literature supported that the physical activity from mild to moderate enhances birth weight, however; severe physical activity will do the opposite effect. ${ }^{11}$ Moreover, in normal-weight women, regular physical activity during pregnancy has been shown to lower the incidence of cesarean deliveries. ${ }^{11}$ However, number of studies have reported unfavorable outcomes associated with physical activity during pregnancy. ${ }^{12-13}$ Considering conflicting results, the impact of physical activity on birth outcomes is still on debate. Saudi Arabia has different culture as compared to Europe and other Far East countries where most studies have been conducted. From Saudi Arabia, no previous study has been identified that evaluated the impact of physical activity on obstetric outcomes. Therefore, the present study was conducted to compare the obstetric outcomes between physically active and nonactive pregnant women. Thus, the study objective was to evaluate the impact of physical activity during pregnancy on obstetric outcomes.

\section{Material And Methods:-}

The cross-sectional study was conducted in the Department of Gynaecology and Obstetrics, King Faisal Maternity Hospital, situated in Taif city, Saudi Arabia from July to December, 2018. Three hundred women from maternity clinic, delivery rooms and those admitted in wards were recruited through non-probability convenience sampling technique. Women who delivered recently of age 18 to 45 years with no psychiatric illness and willing to give informed consent were invited to participate in this research. Women with any ongoing serious medical illness, any obstetric complications, having diseases (i.e. diabetes, hypertension, heart disease) or any adverse condition requiring decreased physical activity were excluded.

Primary data was collected using a structured closed ended questionnaire. The questionnaire consisted of three parts. The first part consisted of socio demographic (i.e. age, education, working status, monthly income of family in 
Saudi Riyal) and maternal characteristics (pregnancy BMI, parity, smoking status, passive smoking status). The second part of the questionnaire collected information about physical activity and level of physical activity. The third part inquired the study participants about the self-reported health status. Finally the last part, retrieved information related to obstetric outcomes (i.e. gestational age at delivery in week, birth weight, living status, admission to Neonatal Intensive Care Unit (NICU) and mode of delivery). The information was collected from the study participants as well as cross checked or retrieved from the patient's file or hospital records. The physical activity was categorized as low and recommended. Physical activity Less than 150 minutes / week was defined as not achieving the recommended level while physical activity greater than or equal to 150 minutes / week was defined as achieving recommended level. ${ }^{10}$

The study is approved by the institutional ethical review committee of King Faisal Hospital, Saudi Arabia. Anonymity and confidentiality of the study participant's data was maintained throughout the research and written informed consent was obtained from all participants prior enrollment in the research.

\section{Data Analysis}

The data was analysed using SPSS version 21 (IBM, Chicago, IL). The data was entered and validated twice for incorrect entries. Descriptive statistics was performed. Quantitative variables (i.e. age in years) were presented as mean \pm standard deviation, while categorical variables were presented as frequency/percentage. The socio demographic characteristics of the study participants (i.e. age categories, education, working status, monthly income, pregnancy, parity, smoking status and passive smoking), physical activity and level of physical activity were presented as frequency/ percentage. The self-reported health status, living status, admission to NICU and mode of delivery between the two groups (physical activity of less than 150 minutes per week or physical activity equal or greater than 150 minute per week) were compared using the chi square statistics. If the assumptions of the chi square statistics was not satisfied Fisher exact test was applied. The gestational age ate delivery in week and birth weight in grams both being quantitative were compared between the two physical activity groups using the independent $t$ test. For inferential statistics the p-value less than 0.05 was considered significant.

\section{Results:-}

The table 1 gives details of the three hundred study participants enrolled in this study. The mean (SD) age in years was 27.3 (4.6). Majority (34\%) of the study participants lied in age category (26-30) years, followed by thirty one to thirty five years $(28 \%)$, eighteen to twenty five years $(23 \%)$ and least in age category of greater than thirty five years $(15 \%)$. Moreover, majority (61\%) of the study participants attended school, while around thirty five percent had education bachelors or above. Furthermore, around forty one percent had family income per month in the range of 5,000 to 10,000 Saudi Riyal, followed by family income per month exceeding SR. 10,000 by one third of study participants, and only twenty six percent had monthly family income less than 5,000 Saudi Riyal. Importantly, majority of study participants during pregnancy were overweight (37\%), followed by normal weight (33\%) and obese $(30 \%)$. Majority of the study participants were multiparous $(51 \%)$, followed by nullparity $(24 \%)$ and grand multipara (25\%). Important, around ninety eight percent of the study participants were non-smokers, while nineteen percent were passive smokers.

Table 1:-Socio demographic and Maternal Characteristics of the Study Participants

\begin{tabular}{|l|c|}
\hline Characteristics & Mean $\mathbf{\pm}$ SD $/ \mathbf{n}(\%)$ \\
\hline Age in years & $27.3 \pm 4.6$ \\
\hline Age categories & $69(23)$ \\
\hline $18-25$ years & $102(34)$ \\
\hline $26-30$ years & $84(28)$ \\
\hline $31-35$ years & $45(15)$ \\
\hline Greater than 35 years & $12(4)$ \\
\hline Education & $183(61)$ \\
\hline Illiterate & $105(35)$ \\
\hline Attended School & \\
\hline Bachelors or above qualification & $246(82)$ \\
\hline Working status & $42(14)$ \\
\hline Housewife & \\
\hline Employed & \\
\hline
\end{tabular}




\begin{tabular}{|l|c|}
\hline Student & $12(4)$ \\
\hline Monthly income of family (SR) & $78(26)$ \\
\hline Less than 5,000 SR & $123(41)$ \\
\hline $5000-10,000$ SR & $99(33)$ \\
\hline More than 10,000 SR & $99(33)$ \\
\hline Pregnancy BMI $\left(\mathrm{kg} / \mathrm{m}^{2}\right)$ & $111(37)$ \\
\hline Normal weight $(<28.4)$ & $90(30)$ \\
\hline Overweight $(28.5-32.9)$ & \\
\hline Obese $(>33)$ & $72(24)$ \\
\hline Parity & $153(51)$ \\
\hline Nullparity $(0$ birth) & $75(25)$ \\
\hline Multiparity $(1-4$ births) & \\
\hline Grand multipara $(\geq 5$ births) & $294(98)$ \\
\hline Smoking status & $6(2)$ \\
\hline Non-smokers & \\
\hline Smokers & $57(19)$ \\
\hline Passive smoking & $243(81)$ \\
\hline Yes & \\
\hline No & \\
\hline
\end{tabular}

The table 2 gives details of the physical activities and level of physical activity as experienced by the study participants. There were only ninety three study participants (31\%) walk in leisure time while only fifty seven (19\%) of the women enrolled walked quickly during leisure time. Moreover, the other physical activities (i.e. swimming, yoga, ball games and cycling) in leisure time were as low as four percent. Importantly, there were only eighty one study participants (27\%) who affirmed managing 150 minutes/ week of moderate/ vigorous physical activities in leisure time. Finally, the level of physical activity identified during pregnancy were as follows; sedentary (73\%), moderately active (19\%) and vigorously active (8\%).

Table 2:-Distribution of Study Participants according to doing Leisure Time Physical Activity and Level of Physical Activity

\begin{tabular}{|l|c|}
\hline Physical Activity & n (\%) \\
\hline Walk in leisure time & $93(31)$ \\
\hline Yes & $207(69)$ \\
\hline No & $57(19)$ \\
\hline Walk quickly in leisure time & $243(81)$ \\
\hline Yes & $12(4)$ \\
\hline No & $288(96)$ \\
\hline Other physical activity in leisure time* & \\
\hline Yes & $81(27)$ \\
\hline No & $219(73)$ \\
\hline $\begin{array}{l}\text { Managing 150 minutes/ week of moderate/ vigorous physical activities in leisure } \\
\text { time }\end{array}$ \\
\hline Yes & $219(73)$ \\
\hline No & $57(19)$ \\
\hline Level of physical activity & $24(8)$ \\
\hline Sedentary/ Not very active & \\
\hline Moderate Active & \\
\hline Vigorously Active & \\
\hline
\end{tabular}

* Swimming, yoga, ball games and cycling

The table 3 compared the self-reported health status during pregnancy by the study participants having less than 150 minutes of physical activity/ week (Group A) to those having 150 minutes or more time spent in physical activity/ week (Group B). Around eighty four percent of the study participants having less than 150 minutes of physical activity/ week had very good or good self-reported health status compared to ninety percent who performed more 
than or equal to study participants having less than 150 minutes of physical activity/ week. Greater proportion of study participants having PA $<150$ minutes / week had poor health status as compared to those having $\geq 150$ minutes of PA/ week $(2.5 \%$ vs. $0.9 \%)$. No statistically significant difference was observed as p-value $=0.369$.

Table 3:-Self-related Health status in two different level of Physical Activity

\begin{tabular}{|c|c|c|c|}
\hline Self- reported Health Status & $\begin{array}{c}\text { Less than } 150 \text { minutes } \\
\text { of PA/ week } \\
\text { (Group A) } \\
\text { n (\%) } \\
(\mathbf{N}=\mathbf{8 1})\end{array}$ & $\begin{array}{c}\text { More than or equal to } 150 \\
\text { minutes of PA/ week } \\
\text { (Group B) } \\
\text { n (\%) } \\
(\mathbf{N}=\mathbf{2 1 9})\end{array}$ & P-value \\
\hline \multicolumn{3}{|l|}{ Self-reported health status } & \multirow{6}{*}{0.369} \\
\hline Very Good & $18(22.2)$ & $53(24.2)$ & \\
\hline Good & $50(61.7)$ & $144(65.8)$ & \\
\hline Neither Good nor Poor & $9(11.1)$ & $20(9.1)$ & \\
\hline Poor & $2(2.5)$ & $2(0.9)$ & \\
\hline Very Poor & $1(1.2)$ & $0(0)$ & \\
\hline
\end{tabular}

The table 4 gives details of the comparison of obstetric outcomes between two groups; Group A (PA $<150$ minutes / week) and Group B ( $\geq 150$ minutes of PA/ week). Significant difference was found in gestational age at delivery in weeks between the two groups ( 39.3 vs. 38.9 ; $\mathrm{p}$-value $=0.0018)$. Significant difference was not observed in obstetric outcomes (birth weights, living status, admission to NICU and mode of delivery) between participants having physical activity less than 150 minutes per week to those having physical activity of 150 minutes or more per week. Though no significant difference was observed in terms of obstetric outcomes but study participants having greater or equal to 150 minutes of physical activity has demonstrated improved obstetric outcomes (i.e. increased living status, lesser admission to NICU, and greater proportion of vaginal non instrumental delivery).

Table 4:-Comparison of Obstetric Outcomes in relation to Physical Activity

\begin{tabular}{|c|c|c|c|}
\hline Obstetric Outcomes & $\begin{array}{c}\text { Less than } 150 \text { minutes } \\
\text { of PA/ week } \\
(\text { Group A) } \\
\text { Mean } \pm \text { SD / n }(\%) \\
(\mathbf{N}=\mathbf{8 1})\end{array}$ & $\begin{array}{l}\text { More than or equal to } 150 \\
\text { minutes of PA/ week } \\
(\text { Group B) } \\
\text { Mean } \pm \text { SD / }(\%) \\
(\mathbf{N}=219)\end{array}$ & P-value \\
\hline Gestational age at delivery (weeks) & $39.3 \pm 0.9$ & $38.9 \pm 1.0$ & 0.0018 \\
\hline Birth weight (grams) & $3551 \pm 521.7$ & $3549.7 \pm 516.4$ & 0.9846 \\
\hline \multicolumn{4}{|l|}{ Living status (Still birth) } \\
\hline Yes & $73(90.1)$ & $208(95)$ & 0.206 \\
\hline No & $8(8.9)$ & $11(5)$ & \\
\hline \multicolumn{4}{|l|}{ Admission to NICU } \\
\hline Yes & $13(16)$ & $19(8.7)$ & 0.104 \\
\hline No & $68(84)$ & $200(91.3)$ & \\
\hline \multicolumn{4}{|l|}{ Mode of delivery } \\
\hline Vaginal non Instrumental delivery & $64(79)$ & $182(83.1)$ & 0.517 \\
\hline Vaginal instrumental/ Caesarean & $17(21)$ & $37(16.9)$ & \\
\hline
\end{tabular}

\section{Discussion:-}

The present descriptive cross-sectional study was conducted to identify the effect of physical activity during pregnancy on obstetric outcomes. Differences was significant in gestational age at delivery in weeks between PA < 150 minutes/ week (Group A) and PA $\geq 150$ minute/ week (Group B), however no significant difference was observed on obstetric outcomes (i.e. birth weight, living status, NICU admission and mode of delivery). However, women with physical activity equal or greater than 150 minute per week had greater proportion of live births, lesser admission to NICU and lesser proportion of instrumental and caesarean section delivery; thereby showing improved obstetric outcomes.

In the current study around twenty seven percent of the study participants attained the recommended 150 minutes/ week of moderate/ vigorous physical activities during pregnancy. This is in accordance with previous studies 
globally, reporting a range of 22 to $42 \%$ of pregnant women meeting the recommended physical activity guidelines. ${ }^{14-16}$ The low participation in physical activity has been explained by a research that indicated that during pregnancy physical activity is performed purposively to perform certain task and not for recreation. ${ }^{17}$ Moreover, evidence also supported that environmental influences (i.e. lack of facilities and opportunities) for pregnant women restrict them to participate in exercise or attaining physical activity recommended level. ${ }^{18}$

A recent study that enrolled 57 pregnant women reported no significant effect of PA duration over occurrence of low birth weight, the gestation age at birth and delivery method. ${ }^{19}$ A meta-analysis that included eight cohort studies reported that PA was inversely associated with inversely associated with birth weight and large for gestational age. ${ }^{20}$ The study from China reported that physical activity of more than 150 minutes/ week had strong influence over the success rate of vaginal birth. ${ }^{21}$ Another study reported that moderate intensity physical activity was associated with birth weight and delivery mode. ${ }^{22}$ A cross-sectional study from Sweden that collected data from 3,868 pregnant women reported $47 \%$ achieving the recommended level of physical activity. ${ }^{23}$ However, significant associations could not be established between level of physical activity with birth weight and mode of delivery. ${ }^{23} \mathrm{~A}$ metaanalysis has reported that maternal exercise during pregnancy was safe and beneficial for fetus. ${ }^{24}$ Moreover, maternal exercise was found associated with reduced odds of macrosomia and was not associated with neonatal complications as well as adverse childhood outcomes. ${ }^{24}$ Another study highlighted that there were no significant differences in the low birth weight, fetal or neonatal death between physically active and non-active pregnant women. $^{25}$ The reported evidence are similar to as identified in the current study where no significant difference was found in living status, admission to NICU, and vaginal non instrumental delivery between pregnant women who achieved recommended physical activity level and those who did no.

The present study conducted had certain limitations. Firstly, as the study participants were recruited through convenience sampling technique, thus induces the chances of sampling bias. Secondly, the women satisfying the eligibility criteria were recruited only from one hospital. Recruitment of study participants from other hospitals from different cities of Saudi Arabia would have improved the generalisibility and external validity of the study findings. Thirdly, questionnaire with binary responses was used to inquire about the physical activity and level of physical activity there have been chances that study participants would have under reported or over reported their level of physical activity during pregnancy. Importantly, being a cross-sectional study design, it is hard to establish a temporal association between physical activity levels and obstetric outcomes, thus the result should be interpreted with caution. Therefore, a cohort study using a validated tool to identify PA (i.e. Pregnancy Physical Activity Questionnaire) at multiple hospital settings with a larger sample and multiple follow-ups is desirable to be conducted to better and precisely identify the impact of physical activity among Saudi pregnant women on obstetric outcomes.

\section{Conclusion:-}

The present study concluded that the level of physical activity had significant impact on gestational age at delivery in weeks. Moreover, the recommended physical activity appeared to improve the obstetric outcomes; birth weight at delivery, living status, reduced NICU admission and mode of delivery as vaginal.

\section{References:-}

1. Blair SN. Physical inactivity: the biggest public health problem of the 21st century. Br J Sports Med. 2009; 43(1):1-2.

2. Caspersen CJ, Powell KE, Christenson GM. Physical activity, exercise, and physical fitness: definitions and distinctions for health-related research. Public Health Rep 1985; 100(2):126-31.

3. Sallis JF, Bull F, Guthold R, et al. Progress in physical activity over the Olympic quadrennium. Lancet. 2016; 388(10051):1325-36.

4. GBD. Global, Regional, and national comparative risk assessment of 79 behavioral, environmental and occupational, and metabolic risks or clusters of risks, 1990-2015: a systematic analysis for the global burden of disease study 2015. Lancet. 2016; 388(10053):1659-1724.

5. Al-Hazzaa HM. The public health burden of physical inactivity in Saudi Arabia. J Fam Commun Med 2004; 11:45-51.

6. Ministry of Health. Survey of Health Information in Kingdom of Saudi Arabia 2013. 
7. Al-Hazzaa HM, Abahussain NA, Al-Sobayel HI, Qahwaji DM, Musaiger AO. Physical activity, sedentary behaviors and dietary habits among Saudi adolescents relative to age, gender and region. Int J Behav Nutr Phys Act. $2011 ; 8(1): 140$.

8. American College of Obstetricians and Gynecologists. Exercise during pregnancy and the postpartum period. Clin Obst Gyne. 2003; 46(2):496.

9. Artal R, O'toole M. Guidelines of the American College of Obstetricians and Gynecologists for exercise during pregnancy and the postpartum period. British journal of sports medicine. 2003; 37(1):6-12.

10. Davies GA, Wolfe LA, Mottola MF, MacKinnon C. Joint SOGC/CSEP clinical practice guideline: exercise in pregnancy and the postpartum period. Canadian Journal of Applied Physiology. 2003; 28(3):329-41.

11. Dwarkanath P, Muthayya S, Vaz M, Thomas T, Mhaskar A, Mhaskar R, Thomas A, Bhat S, Kurpad A. The relationship between maternal physical activity during pregnancy and birth weight. Asia Pacific journal of clinical nutrition. 2007; 16(4):704-10.

12. Ahlborg Jr G, Bodin L, Hogstedt C. Heavy lifting during pregnancy-a hazard to the fetus? A prospective study. International Journal of Epidemiology. 1990; 19(1):90-7.

13. Palmer KT, Bonzini M, Harris EC, Linaker C, Bonde JP. Work activities and risk of prematurity, low birth weight and pre-eclampsia: an updated review with meta-analysis. Occup Environ Med. 2013; 70(4):213-22.

14. Poudevigne MS, OConnor PJ. A review of physical activity patterns in pregnant women and their relationship to psychological health. Sports Med. 2006; 36(1):19-38.

15. Evenson KR, Wen F. National trends in self-reported physical activity and sedentary behaviors among pregnant women: NHANES 1999-2006. Preventive Med. 2010; 50(3):123-8.

16. Borodulin K, Evenson KR, Wen F, Herring AH, Benson A. Physical activity patterns during pregnancy. Medicine and Science in Sports and Exercise. 2008; 40(11):1901.

17. Kruger HS, Venter CS, Vorster HH, Margetts BM. Physical inactivity is the major determinant of obesity in black women in the North West Province, South Africa: the THUSA study. Nutrition. 2002; 18(5):422-7.

18. Muzigaba M, Kolbe-Alexander TL, Wong F. The perceived role and influencers of physical activity among pregnant women from low socioeconomic status communities in South Africa. Journal of Physical Activity and Health. 2014; 11:1276-83.

19. Mizgier M, Mruczyk K, Jarzabek-Bielecka G, Jeszka J. The impact of physical activity during pregnancy on maternal weight and obstetric outcomes. Ginekol Pol. 2018; 89(2):80-8.

20. Pastorino S, Bishop T, Crozier SR, Granström C, Kordas K, Küpers LK, et al. Associations between maternal physical activity in early and late pregnancy and offspring birth size: remote federated individual level metaanalysis from eight cohort studies. BJOG Int J Obstet Gynaecol. 2019; 126(4):459-70.

21. Qi X-, Xing Y-, Wang X-, Yang F-. Examination of the association of physical activity during pregnancy after cesarean delivery and vaginal birth among Chinese women. Reprod Health. 2018; 15(1).

22. Chen C-, Tzeng Y-, Ying T-, Kuo P-. The relationship among physical activity during the third trimester, maternal pre-pregnancy body mass index, gestational weight gain, and pregnancy outcomes. J Nurs. 2017; 64(1):80-9.

23. Lindqvist M, Lindkvist M, Eurenius E, Persson M, Ivarsson A, Mogren I. Leisure time physical activity among pregnant women and its associations with maternal characteristics and pregnancy outcomes. Sex Reprod Health. 2016; 9:14-20.

24. Davenport MH, Meah VL, Ruchat S-, Davies GA, Skow RJ, Barrowman N, et al. Impact of prenatal exercise on neonatal and childhood outcomes: A systematic review and meta-analysis. Br J Sports Med. 2018; 52(21):138696.

25. Rose NC, Haddow JE, Palomaki GE, Knight GJ. Self-rated physical activity level during the second trimester and pregnancy outcome. Obstet Gynecol. 1991; 78(6):1078-80. 